\title{
1 Sensory Ecology of Ostariophysan Alarm Substances
}

2 Caio Maximino ${ }^{1}$, Rhayra Xavier do Carmo Silva ${ }^{1,2}$, Kimberly dos Santos Campos ${ }^{3}$, Jeiseane Souza

3 de Oliveira ${ }^{3}$, Sueslene Prado Rocha ${ }^{3}$, Maryana Pereira Pyterson ${ }^{1}$, Dainara Pereira dos Santos

4 Souza $^{1}$, Leonardo Feitosa Miranda ${ }^{3}$, Saulo Rivera Ikeda ${ }^{3}$, Ana Flávia Nogueira Pimentel ${ }^{1}$, Pâmila

5 Nayana Ferreira Ramos ${ }^{3,4}$, Bruna Patrícia Dutra Costa ${ }^{1,4}$, Anderson Manoel Herculano ${ }^{5}$, Denis

6 Broock Rosemberg ${ }^{6}$, Diógenes Henrique Siqueira da Silva ${ }^{1}$, Monica Lima Maximino ${ }^{3}$

7

$8{ }^{1}$ Laboratório de Neurociências e Comportamento "Frederico Guilherme Graeff", Instituto de

9 Estudos em Saúde e Biológicas, Universidade Federal do Sul e Sudeste do Pará

$10{ }^{2}$ Programa de Pós-Graduação em Neurociências e Biologia Celular, Instituto de Ciências

11 Biológicas, Universidade Federal do Pará

$12{ }^{3}$ Laboratório de Neurofarmacologia e Biofísica, Departamento de Morfologia e Ciências

13 Fisiológicas, Universidade do Estado do Pará - Campus VIII/Marabá

$14{ }^{4}$ Rede de Biodiversidade e Biotecnologia da Amazônia Legal

$15{ }^{5}$ Laboratório de Neurofarmacologia Experimental, Instituto de Ciências Biológicas, Universidade

16 Federal do Pará

$17{ }^{6}$ Laboratório de Neuropsicobiologia Experimental, Departamento de Bioquímica e Biologia

18 Molecular, Centro de Ciências Naturais e Exatas, Universidade Federal de Santa Maria

19

20 


\section{Abstract}

22 Chemical communication of predation risk has evolved multiple times in fish species, with the

23 conspecific alarm substance (CAS) contemporaneously being the most well understood mechanism.

24 CAS is released after epithelial damage, usually when prey fish is captured by a predator, and elicits

25 neurobehavioral adjustments in conspecifics which increase the probability of avoiding predation.

26 As such, CAS is a partial predator stimulus, eliciting risk assessment-like and avoidance behaviors,

27 and disrupting the predator sequence. The present paper reviews the distribution and putative

28 composition of CAS in fish, and presents a model for the neural processing of these structures by

29 the olfactory and the brain aversive systems. Applications of CAS in the behavioral neurosciences

30 and neuropharmacology are also presented, exploiting the potential of model fish (e.g., zebrafish,

31 guppies, minnows) on neurobehavioral research.

32 Keywords: Alarm substance; Alarm signals; Disturbance signals; Fish; Ostariophysi

\section{1. Introduction}

Each species possess specific (tactile, acoustic, chemical) and cross-model communication channels for different finalities. For fish, chemical communication in the aquatic environment causes behavioral adjustments and shifts that require the transfer of adaptive information between senders and receivers. This communication has different aims: demarcation of territory, sexual

39 attraction, food signaling, danger signals, among others (Liley, 1982).

41 attack by avoiding an encounter or escaping capture. The methods and resources available to alert

42 conspecifics are species-specific and vary according to context and other factors. In order for these

43 "predator alert" signals to be conveyed, the central nervous system and sense organs evolved 44 (Pfeiffer, 1977; Liley, 1982). In fish, chemical communication of predation risk has evolved 
45 multiple times in the form of conspecific alarm substances (CASs) and disturbance signals (DSs; 46 see Box 1).

47 Conspecific alarm substances were first described by Karl von Frisch $(1938,1941)$ using the 48 Eurasian minnow Phoxinus phoxinus. von Frisch described that these fish "seem terrified" when a 49 skin extract produced from conspecifics was introduced, fleeing a short distance "in confusion, 50 increasing shoal cohesion, and retreating. Later, it was observed that most Ostariophysans display a 51 "fright-like" alarm response towards CAS (von Frisch, 1941; Pfeiffer, 1977; Smith, 1992; 52 Jesuthasan \& Mathuru, 2008; Døving \& Lastein, 2009), although considerable interspecific 53 variation is observed (see Box 2 for experimental findings on zebrafish and fathead minnows): 54 some species can display thrashing against the tank bottom, swimming with their heads against the 55 bottom and their bodies at an angle to the floor; some species may display prominent freezing (i.e., 56 become motionless for extended periods of time); some species may display extensive bottom-

57 dwelling, with special gases in which the fish starts spitting gas for a considerable time; and some 58 may display surfacing behavior, crowding together at the surface and attempting to jump out of the 59 water (Pfeiffer, 1977). Later, it has also been shown that some non-Ostariophysan fish also display 60 CAS.

In Ostariophysans, CAS is produced on specialized club cells in the epidermis (Pfeiffer, 62 1977) that, when damaged, release the substance (a "signal", in Smith's (1992) terminology) into 63 the water, initiating alarm reactions in conspecifics. Whether or not the animal that produces and 64 releases CAS (termed "sender", follow Smith (1992)) also benefits from the transmission is as of 65 yet unresolved. von Frisch (1941) was also the first to demonstrate that CAS is an olfactory signal, 66 demonstrating the importance of this sensory channel for ecological interactions in Ostariophysans. While the term "alarm substance" is now widespread, in order for a given mechanism to 68 classify as an alarm signal, it needs to be produced by the sender when it detects threat; it also needs 69 to be detected by receivers (ideally conspecifics) in a way that they react in a way that is similar to 
70 their reaction to actual threats (Smith, 1992). Indeed, CAS is best defined as a "partial predator

71 stimulus" (Dielenberg \& McGregor, 2006) in that it does not faithfully signals the presence of a

72 predatory threat, but instead signals a potential threat. As such, differently from other ecologically

73 relevant sensory signals, CAS increases uncertainty instead of reducing it, producing behavioral

74 adjustments that decrease the probability of an (uncertain) capture.

The present review attempts to capture the complexity of responses to conspecific alarm

substances in fish, including the behavioral characteristics of the alarm reaction, the mechanisms of

77 its detection by the olfactory system, the mechanisms of response production by the aversive brain 78 system, and potential applications in the fields of behavioral neuroscience and 79 neuropsychopharmacology.

\section{Phylogenetic distribution of CAS}

First described in cyprinids (von Frisch, 1938, 1941), later it was shown that CAS is

83 produced by most fish from the superorder Ostariophysi (Pfeiffer, 1977). The presence of club cells,

84 a specialized epidermal cell with high cytoplasm-to-nucleus ratio that lacks porous openings to the exterior, is thought to be crucial in this superorder (Pfeiffer, 1977). Damage to these club cells normally after being captured by a predator - leads to the release of alarm substance; as such, CAS cannot be released voluntarily.

Alarm reactions have also been observed in a few non-Ostariopysan fishes, although that appears to be an exception (Pfeiffer, 1977). While most percomorpha did not display an alarm reaction or club cells (Pfeiffer, 1977), alarm reactions have been described in the perciforms Nile

91 tilapia (Oreochromis niloticus) (Sanches et al., 2015; Silva et al., 2015), Mozambique tilapia

92 (Oreochromis mossambicus) (Jaiswal \& Waghray, 1990), convict cichlids (Amatitlania 93 nigrofasciatus) (Alemadi \& Wisenden, 2002), and in the fillfrin goby (Bathygobius soporator) 
94 (Barreto et al., 2014), suggesting that this response evolved independently multiple times in this 95 clade.

96 Curiously, some poeciliids display an alarm reaction to conspecific skin extracts, even if

97 club cells cannot be identified in the species (Pfeiffer, 1977). Similarly, the medaka (Oryzias latipes,

98 Beloniformes) show freezing episodes to conspecific skin extract and increased whole-body cortisol

99 levels, but appear to lack club cells (Mathuru, 2016). However, since there are no positive markers

100 to club cells in histological slides, it is hard to properly ascertain the lack of such cells. Nonetheless,

101 it seems that alarm substances evolved multiple times in fish, and was probably present at the root

102 of the Ostariophysan superorder. Most alarm substances appear to be released by damage to club

103 cells, but the existence of alarm reactions without club cells is also possible, especially in non-

104 Ostariophysi.

105

106 3. Chemical composition of conspecific alarm substances

The exact composition of CAS is as of yet unknown. Hüttel (1941) already reported that

108 nitrogen compounds were likely to be important, assuming that purine- and pterin-like substances to

109 be the main components of CAS. Attempts to describe a single compound all failed, and soon it was

110 clear that multiple odorants make up conspecific alarm substances (Døving \& Lastein, 2009). Alarm

111 reactions could be elicited in zebrafish (Danio rerio), fathead minnows (Pimephales promelas), and

112 finescale dace (Chrosomus neogaeus) when exposed to hypoxanthine-3- $N$-oxide (H3NO) or the

113 functionally similar pyridine- $N$-oxide, but not to structurally similar molecules that lacked nitrogen

114 oxide-based functional groups (Pfeiffer \& Riegelbauer, 1984; Brown et al., 2000; Parra et al., 2009;

115 Mathuru et al., 2012). Nonetheless, at least in zebrafish H3NO elicits some, but not all, components

116 of the alarm reaction (Parra et al., 2009; Mathuru et al., 2012), and therefore it is expected to be one

117 in a cocktail of substances in CAS. 
118 Further clues were obtained by fractioning the brute skin extract of zebrafish by anion

119 exchange chromatography and high-performance gel filtration, which produced fractions which

120 were able to elicit clear behavioral responses in zebrafish (Mathuru et al., 2012). A fraction with

121 high molecular weight was found, through mass spectrometry, to contain long polymers, including

122 chondroitin glycosaminoglycans (Mathuru et al., 2012). Indeed, heavy molecular weight

123 chondroitin sulfate fragments were able to induce a robust alarm reaction in zebrafish (Mathuru et

124 al., 2012), as well as increasing fos expression in the dorsomedial olfactory bulb (DeCarvalho et al.,

125 2013). These results suggest that both glycosaminoglycans and nitrogen oxide-based purines and

126 pterins to be important for CAS signaling.

\section{CAS disrupts the predation sequence}

Irrespective of what is the evolutionary pressures which resulted in the evolution of an alarm

130 signal in fish, it has long been understood that CAS disrupts the predation sequence at multiple 131 points (von Frisch, 1941; Smith, 1992). Lima \& Dill (1990) suggested that a predation sequence 132 develops from a predator-prey encounter that (if the prey is first detected by the predator) can 133 evolve to an attack that is followed by either escape or capture (Figure 1). Using Fanselow's 134 terminology (Fanselow \& Lester, 1988; Perusini \& Fanselow, 2015), from pre-encounter defensive 135 behaviors (meal reorganization, careful exploration of non-safe environments) the sequence 136 develops to post-encounter defense (aimed at avoiding detection and attack), followed by circa137 strike defensive behavior (including attempts to flee or attack the predator)(Figure 1). Smith (1992), 138 in a now classical review, suggested that CAS acts at the second level (post-encounter defense) to 139 decrease the probability that the conspecific is detected first and increase the probability that it 140 detects the predator first.

CAS is a "partial predator stimulus" (Dielenberg \& McGregor, 2006) - that is, it does not

142 faithfully communicates the presence of a predator, since injury could happen from other sources. 
143 In rodents, partial predator stimuli induce risk assessment-like responses (i.e., pre-encounter

144 defensive behaviors) instead of altering post-encounter defense (Dielenberg \& McGregor, 2006).

145 This is because partial predator stimuli increase uncertainty, since the threat is merely potential (that

146 is, the predator might be or might not be present), and since the direction of the threat is difficult to

147 discern; as a result, careful assessment of the environment is necessary. While CAS certainly fulfills

148 the criteria for a partial predator stimulus at the "signal" side, it does not appear to affect pre-

149 encounter defensive behaviors in fish, instead increasing post-encounter defense (Box 2).

150

151 5. Adaptive and evolutionary issues for alarm signals

152 While it appears clear that CAS is a partial predator stimulus that induces defensive 153 responses (Box 2), there is still some controversy in the field as to what is the evolutionary role of

154 CAS. The question was introduced by R. Jan F. Smith in 1992, and has not yet been answered. Two

155 hypothesis are more prominent, the kin selection hypothesis, and the predator attraction hypothesis.

156 In the first case, centered on W. D. Hamilton's theory of kin selection (Hamilton, 1963), since the

157 sender of CAS is paying a high cost because it releases the chemical signal due to potentially mortal

158 damage, the benefits to related individuals (kins) would need to be sufficiently high. Under this

159 hypothesis, CAS benefits kin, and not the sender, because closely related individuals are more likely

160 to share alleles by common descent, and therefore the frequency of the sender's alleles in the next

161 generation would be increased by increasing kin's survival probabilities.

162 The application of the kin selection hypothesis to the evolution of CAS necessitates at least

163 two assumptions (Smith, 1992): first, there should be evidence that CAS release increases the

164 receivers' fitness; secondly, it should be shown that individuals in a given species associate mainly

165 with kin. There is now ample evidence that CAS increases vigilance, leading to antipredator

166 behavior such as that described in Box 2, as well as long-term alterations in foraging (Oswald \&

167 Robison, 2011), fear-induced analgesia (Maximino, 2011; Maximino et al., 2014), and avoidance of 
168 areas in which CAS is detected (Chivers \& Smith, 1994; Wisenden et al., 1995) or which were

169 previously associated with CAS (Ruhl et al., 2017; Maximino et al., 2018). Guppies (Poecilia

170 reticulata) exposed to CAS are more attentive to visual cues (Stephenson, 2016), and zebrafish

171 (Danio rerio) exposed to CAS show increased risk assessment in the light/dark test (Quadros et al.,

172 2016; but see Maximino et al., 2014), suggesting that CAS increases alertness to threatening cues in

173 other sensory modalities. On the other hand, CAS was not able to increase antipredator responses to

174 a sympatric predator (although the predator was not in the same tank as the receiver) in zebrafish

175 (Speedie \& Gerlai, 2008), although CAS increased survival of fathead minnows (Pimephales

176 promelas) placed in an experimental tank with a predator (Mathis \& Smith, 1993). Moreover,

177 zebrafish given visual and olfactory access to conspecifics show less freezing when exposed to CAS

178 (Faustino et al., 2017), an effect that has been termed "social buffering". This observation, as well

179 as the fact that zebrafish tested in groups are less likely to freeze, suggest that conspecific

180 communication is the main function of CAS. Indeed, freezing in a shoal would be maladaptive,

181 since the frozen animal would be more likely to be attacked by the predator than its conspecifics.

182 Therefore, being able to adapt its behavioral response - from freezing to shoal cohesion and erratic

183 swimming - increases the ability of the animal to survive.

184 The second condition for the kin selection hypothesis of CAS evolution is that individuals

185 should prefer to shoal with kin rather than non-kin. There is mixed support for this hypothesis. For

186 example, there is evidence that zebrafish displays a preference for water in which kin has previously

187 resided over water inhabited by non-kin and unfamiliar kin (Gerlach \& Lysiak, 2006). On the other

188 hand, in European minnows (Phoxinus phoxinus), no evidence for a preference for kins was found

189 within and between shoals (Naish et al., 1993). Moreover, in fathead minnows the presence of

190 familiar shoalmates is associated with less epidermal club cells (Wiseden \& Smith, 1998).

191 Glaringly, to the best of our knowledge it is not yet known, in any fish species, whether kin are 
192 more responsive to CAS than non-kin, which could increase support to the kin selection hypothesis

193 of CAS evolution.

194 The competing hypothesis, the predator attraction hypothesis, suggests that CAS attracts

195 additional predators to the area, promoting interactions between the new and the original predator

196 and allowing the sender an opportunity to escape (Smith, 1992). Again, this competing hypothesis

197 carries two important assumptions: the first is that CAS must attract predators; the second is that

198 subsequent predators should disrupt the initial predation encounter, increasing escape probability.

199 Moreover, the sender must be able to recover from the damage in order to escape.

200 There is some evidence that at least some predator species are able to detect alarm signals,

201 and are actively attracted to them. CAS produced from fathead minnows attracted both predatory

202 fish (Esox lucius) and diving beetles (Colymbetes sculptilis) (Mathis et al., 1995). Predator

203 attraction to fathead minnow CAS has also been verified in the field, where predators were 7 times

204 more likely to strike a lure that was baited with minnow CAS than with water or with skin extract

205 from convict cichlid (Amatitlania nigrofasciata)(Wiseden \& Thiel, 2002), which presumably do not

206 produce CAS. Thus, at least preliminary support for the first supporting assumption of the predator

207 attraction hypothesis exists.

208 The second assumption is that additional predators must be able to disrupt predation events

209 in some way, increasing escape probability. It has been shown that the probability of fathead

210 minnows escaping after being captured by a predatory fish is increased by interference by a second

211 pike (Chivers et al., 1996), although the relationship between this event and CAS release has not

212 been investigated. Moreover, only very indirect evidence exists that fish recover from attacks at a

213 high enough probability in order for this hypothesis to be verified; for example, many small fishes

214 in natural populations exhibit scars, presumably from failed predator attempts (Smith \& Lemly,

215 1986). As it stands, there is no strong evidence for either hypothesis on the evolution of CAS. 
A third hypothesis of the evolutionary history of CAS is the immune hypothesis. The

217 hypothesis is based on the observation that parasites and pathogens that penetrate the skin of

218 Ostariophysans stimulate the production of club cells (Chivers et al., 2007). This hypothesis states

219 that the primary function of CAS is immune, providing protection against parasites and pathogens,

220 and the sensory ecological ramifications of the substance as an alarm substance evolved

221 subsequently (Chivers et al., 2007). Supporting this hypothesis, skin extracts from fathead

222 minnows, but not from Xiphophorus helleri (which are believed to not produce CAS), increased the

223 in vitro growth of Saprolegnia ferax (Chivers et al., 2007). Moreover, fathead minnows treated with

224 chronic cortisol show reduced club cells in conjunction with reduced leukocyte activity

225 (Halbgewachs et al., 2009). However, a comparative analysis of the roles of CAS on closely-related

226 species - which could clarify the evolutionary history of this trait - is still needed.

\section{6. Mechanisms of CAS detection}

Differently from most vertebrates which communicate via semiochemicals, there is no

evidence that Ostariophysan fishes posses a true vomeronasal olfactory system (Eisthen, 1992;

Ubeda-Bañon et al., 2011; Maximino et al., 2013). Nonetheless, there is some degree of specialization in olfactory epithelia, as well as in projections of the olfactory system, regarding alarm substances in Ostariophysi (Døving \& Lastein, 2009; Bazáes et al., 2013; Kermen et al., 234 2013).

Odors in the Ostariophysan olfactory epithelium are detected in a combinatorial manner by receptors expressed on olfactory sensory neurons (Kermen et al., 2013). The paired olfactory rosettes, located in the dorsal region of the head near the eyes, contain sensory and non-sensory

238 cells and receptor neurons in the medial region of each lamella. There are three types of olfactory 239 receptor neurons (ORNs) in the Ostariophysan olfactory rosette: ciliated neurons, which have long 240 dendrites and express G-protein coupled odorant receptors; microvillous neurons that express the 
241 V2R-like class of receptors; and crypt cells, which express V1R- type receptors (Whitlock, 2006;

242 Oka \& Korsching, 2011).

243 Unlike mammals, in fish a same sensory neuron can express more than one receptor protein

244 (Kermen et al., 2013). Studies using immunohistochemistry have shown that crypt neurons in

245 zebrafish express Gai proteins (ora4) along with V2R (Oka \& Korsching, 2011; Oka et al., 2012),

246 and the detection of the alarm extracts appears to be mediated by crypt cells (Mathuru et al., 2012;

247 DeCarvalho et al., 2013). These cells present a globose morphology and the appearance of both

248 microvilli and cilia within a crypt and form a small agglomeration in the superficial region of the

249 olfactory epithelium (Hansen \& Zeiske, 1998). Hamdani \& Døving (2002) demonstrated in the

250 crucian carp Carassius carassius that the response alarm is mediated by ciliated neurons that project

251 to olfactory bulb (OB), which suggests that in the different species of fish, the detection of the

252 alarm odorants can be mediated by different sensory neurons (Figure 2).

253 ORNs have fine axons that terminate in the olfactory bulb in specific synaptic structures

254 known as glomeruli (Braubach et al., 2012), which contact dendrites of mitral cells, the output cell

255 of the olfactory bulb (Kermen et al., 2013). The projection from the olfactory epithelium segregates

256 at different targets in the olfactory bulb (OB); in zebrafish, for example, it has been shown that

257 ciliated cells preferentially innervate the dorsal and anteromedial glomerular fields (Gayoso et al.,

258 2012), while crypt ORNs project mainly towards the dorsomedial field (Sato et al., 2005; Gayoso et

259 al., 2011, 2012). A subset of crypt cells respond to kin odors in zebrafish (Biechl et al., 2017),

260 Mathuru et al (2012) demonstrated, through wide-field fluorescence microscopy, that pattern of

261 zebrafish OB activation by partially purified skin extracts involve three distinct loci, located in the

262 anterior plexus, the lateral chain, and the mediodorsal posterior bulb. Interestingly, neurons in the

263 dorsomedial field that project to the habenula, an important structure in the mediation of behavioral

264 responses to CAS (see below), do not show increased fos expression after alarm substance

265 (DeCarvalho et al., 2013). In crucian carp, crypt cells project preferentially towards the ventral OB 
266 (Hamdani \& Døving, 2006); nonetheless, single unit responses to CAS were observed mainly in the

267 dorsomedial field as well (Lastein et al., 2008). Extracellular recordings of nervous activity of units

268 composed of mitral cells in alarm region of OB concomitant stimulation at the olfactory epithelium

269 by skin extracts showed that several of these units respond to and discriminate between conspecific

270 and heterospecific skin extracts (Lastein et al., 2008). However, although the number of units

271 activated was more elevated when stimuli were applied in high concentrations, at low

272 concentrations, the units in the alarm region showed increased discrimination between conspecific

273 and heterospecific skin extracts (Lastein et al., 2008). In this species, CAS elicited an increase in the

274 firing of "type I" cells in the medial field (Hamdani \& Døving, 2003), which are characterized by a

275 diphasic action potential with a relatively small amplitude, a short duration, and high spontaneous

276 activity (Hamdani \& Døving, 2003).

The mitral cells of the OB extend their axons through the medial (MOT) and lateral

278 olfactory tracts (LOT) to different higher brain centers; in carp and zebrafish, the LOT contains

279 mainly fibers originating in lateral domains of the OB, while the MOT contains mainly fibers

280 originating in medial domains (Kermen et al., 2013). The teleost MOT is subdivided into medial

281 and lateral regions (Kermen et al., 2013). In crucian carp, lesions of the medial bundle of the MOT,

282 leaving the lateral bundles intact, abolish alarm reactions to skin extract, demonstrating the

283 specificity of the spatial aspect of olfactory processing (Hamdani et al., 2000).

OB projections reach mainly the posterior zone of dorsal telencephalic area (Dp), the ventral

zone of the ventral telencephalic area $(\mathrm{Vv})$, the medial comparment of the right habenula $(\mathrm{MdHb})$,

286 the posterior tuberculum (PT), and the hypothalamus (Hyp), with secondary projections from the

287 PT to the mesencephalon and reticulo-spinal motor nuclei (Kermen et al., 2013). After entering the

288 telencephalon, the zebrafish MOT initially runs laterally to $\mathrm{Vv}$ and then rises laterally to the dorsal

289 zone of the ventral telecephalic area (Vd) up to commissural levels (Biechl et al., 2017). At

290 postcommissural levels, the MOT forms a large terminal field covering the postcommissural zone 
291 of the ventral telencephalic area $(\mathrm{Vp})$ and the intermediate zone of the ventral telencephalic area

292 (Vi) (Biechl et al., 2017). The participation of these regions, as well as their projections, in the

293 alarm reaction will be the topic of the next section.

\section{8. Neural bases of the alarm reaction}

After detection and initial processing by the olfactory system, CAS initiates an alarm reaction that can be mediated by other structures. Using the expression of $c f o s$, an immediate early gene, some regions which were activated by CAS were identified in zebrafish (Faustino et al., 2017; Ruhl et al., 2017), and include the medial zone of the dorsal telencephalon (Dm, homologous to the mammalian basolateral amygdala [Maximino et al., 2013]), Vv, Vp, and preoptic area (POA, partially homologous to the mammalian hypothalamic paraventricular nucleus [Goodson \& Kingsbury, 2013]). These regions are part of a brain aversive system (Figure 3) that detects aversive stimuli and integrates neurobehavioral responses in fish. Interestingly, while these regions were activated by CAS exposure in zebrafish, the correlation between them decreased (Faustino et al., 2017), suggesting that inhibitory connections are important for the regulation of the activity of these 306 regions.

These regions receive primary or secondary projections from the central olfactory system

308 (Folgueira et al., 2004; Miyasaka et al., 2009; Gayoso et al., 2011). Vv (the putative homologue of 309 the striatum [O’Connell \& Hofmann, 2011; Goodson \& Kingsbury, 2013]) and Vp (a partial 310 homologue of the central amygdala [Maximino et al., 2013]) receive direct projections from the OB 311 via MOT (Biechl et al., 2017). Interestingly, an olfactory projection from the OB to the medial zone 312 of the dorsal right habenula ( $\mathrm{dHbM}$ ) has been described in zebrafish (Miyasaka et al., 2009), but the 313 OB zones which originate this projection are not activated by CAS or chondroitin sulfate 314 (DeCarvalho et al., 2013). Likewise, DeCarvalho et al. (2013) did not identify cfos expression in 315 any zone of the habenula after CAS or chondroitin sulfate exposition. 
This lack of habenular activity is a paradox, given the observation of a role of this structure

317 in organizing olfactory-driven behaviors (Krishnan et al., 2014) and its role in regulating aversive

318 behaviors in zebrafish (Agetsuma et al., 2010; Okamoto et al., 2011; Amo et al., 2014; Chou et al.,

319 2016). The habenular complex is a paired structure found in the diencephalon of all vertebrates,

320 connecting the forebrain to the midbrain. Teleostean habenulas are asymmetric and may contribute

321 to lateralized behavior. The dorsal zone can be subdivided into asymmetric subnuclei, based on their

322 different molecular properties (Halpern et al., 2003; Okamoto et al., 2011). Silencing the dHb in

323 adult zebrafish increased the response to a low CAS concentration (Mathuru \& Jesuthasan, 2013). A

324 dHbL-intermediate interpeduncular nucleus-central gray pathway switches behavior between

325 offensive and defensive behavior, while a dHbM-ventral interpeduncular nucleus-median raphe

326 nucleus (MRN) pathway controls serotonin release and resilience to aversive stimuli (Amo et al.,

327 2014; Chou et al., 2016). The ventral habenula (vHb), on the other hand, does not appear to be

328 lateralized in zebrafish, and tonic responses in the zebrafish $\mathrm{vHb}$ represent an aversive expectation

329 value, participating in a larger vHb-MRN circuit (Amo et al., 2014).

330 In zebrafish, kiss 1 and the kissr 1 receptor are predominantly expressed in the $\mathrm{vHb}$ (Ogawa et

331 al., 2012; Ogawa \& Parhar, 2013; Nathan et al., 2015b). vHb projects Kiss1-expressing neuronal

332 fibers to the MRN (Servili et al., 2011; Ogawa et al., 2012; Nathan et al., 2015b), one of the

333 important conserved serotonergic (5-HTergic) nuclei in the zebrafish (Lillesaar, 2011). Intracerebral

334 administration of Kiss1 significantly reduced the freezing and erratic swimming behaviors evoked

335 by CAS; however, injection of kisspeptin conjugated with saporin (to selectively inactivate Kiss-

336 R1-expressing neurons) decreases non-stimulated cfos activity in both $\mathrm{vHb}$ and $\mathrm{MRN}$, and also

337 abolishes the behavioral effects of CAS (Ogawa et al., 2014). This suggests that kiss1 decreases

338 responsiveness to CAS in $\mathrm{vHb}$ targets such as the MRN, but increase it (via Kiss-R1) in the $\mathrm{vHb}$.

339 Indeed, chronic (8 days) exposure to CAS reduced the expression of kiss 1 in the zebrafish brain, as

340 well as genes associated with 5-HTergic signaling (Ogawa et al., 2014). 
Strengthening the hypothesis of a mediation by the serotonergic system is the observation

\section{2}

343

344 that CAS-induced geotaxis is blocked by kiss1, and that this effect is itself blocked by both 5-HT $1 \mathrm{~A}$ and 5- $\mathrm{HT}_{2}$ receptor antagonists in zebrafish (Nathan et al., 2015a). Interestingly, methysergide, the 5- $\mathrm{HT}_{2}$ antagonist, was also able to block the effects of Kiss1 on CAS-induced freezing, an effect which was not observed with the 5-HT $1 \mathrm{~A}$ receptor antagonist WAY 100,635 (Nathan et al., 2015a). Moreover, both drugs dose-dependently increased the effects of CAS on geotaxis and freezing, but methysergide produced effects at all doses, while WAY 100,635 only produced an effect at a very high dose (Nathan et al., 2015a). Lower doses of WAY 100,635 were unable to block the poststimulation effects of CAS on the light/dark test, and did not block the CAS-elicited sympathetic activation, but were able to block the antinociceptive effect of CAS (Maximino et al., 2014); on the other hand, acute fluoxetine was able to block post-stimulation effects of CAS on the light/dark test and the sympathoactivation, but not the antinociceptive effect (Maximino et al., 2014).

The activation of the POA that is observed after CAS exposure is possibly related to the neuroendocrine profile that is observed in CAS-exposed animals. Increases in cortisol levels were observed after CAS (Mathuru et al., 2012; Schirmer et al., 2013; Silva et al., 2015; Abreu et al., 2017) and disturbance signals (Barcellos et al., 2011, 2014, Oliveira et al., 2013, 2017; see Box 2) in different species. Moreover, in zebrafish CAS elevates plasma levels of norepinephrine, epinephrine, and glucose (Maximino et al., 2014), strongly implicating the sympathetic system in these vegetative adjustments. In spite of these observations, a causal relationship between cortisol and/or plasmatic catecholamines and the alarm reaction has not, so far, been established.

A limitation in the approaches to describing the circuitry involved in the alarm reaction is that they purposefuly analyzed only a handful of regions to increase power; as such, there are many structures which have not been analyzed, but which interact with this "core circuit" (Figure 3). The main region in the interpretation of threatening stimulus is the Dm, the homologue of the mammalian basolateral amygdala. This structure projects to the precommissural (Vs) and 
366 supracommissural $(\mathrm{Vp})$ zones of the ventral telecephalon, which by its turn project (putatively

367 inhibitory) axons to the ventral ( $\mathrm{Vv}$ ), intermediate (Vi), and lateral (Vl) zones of the ventral

368 telencephalon, to the habenula $(\mathrm{Hb})$, and to the preoptic area (POA). Other projections from Vs

369 include the caudal hypothalamus (Hc), optic tectum (OT), and central gray (GC). The POA and the

370 Hc generate the vegetative outputs of CAS (cortisol and norepinephrine/epinephrine release), while

371 OT and GC generate the behavioral outputs (fight/flight/freeze). The inhibitory projection to the

372 habenula could explain the failure to find $c f o s$ activation in this region in spite of its participation in

373 regulating the alarm reaction. As a result of this inhibition, vHb-MRN tonus would decrease,

374 leading to a reorganization of behavior towards risk assessment and freezing.

375 Other neurochemical systems have also been implicated in the alarm reaction. In zebrafish,

376 CAS reduces AMP hydrolysis, an important source of adenosine in the brain (Canzian et al., 2017).

377 Since adenosine appears to exert an anxiolytic-like effect via the A1 and A3 receptors (Maximino et

378 al., 2011, 2015), a down-regulation of this pathway could represent an important mechanism of

379 anxiogenesis. Finally, THC has been shown to impair the acquisition of a conditioned fear response

380 to a visual stimulus that was paired with CAS on zebrafish, and also attenuated the behavioral

381 responses during CAS exposure (Ruhl et al., 2017). Interestingly, THC treatment also reduced

382 CAS-elicited c-Fos expression in the Dm and Dl after conditioning in these animals (Ruhl et al.,

383 2017), suggesting that cannabinoids impair stimulus encoding in these pallial areas. However,

384 whether endocannabinoids participate in the organization of alarm reactions is so far unknown.

\section{Applications of the alarm reaction: Models for panic disorder and PTSD in zebrafish}

The observation of the different behavioral and neuroendocrine effects of CAS suggest its

388 use as a stressful stimulus in modeling threat- and stress-related disorders in fish. Stress reactions

389 and reactions to acute threat are related to several factors, not just those caused by the aggression by

390 other bodies and physical agencies, but also the consequences to man's ability to interpret 
391 syndromes as indications of danger derived from their past experience (Weiss, 1968; Coppens et al., 392 2010; Koolhaas et al., 2010).

393 Given that CAS is a partial predator stimulus that signals a potentially life-threatening 394 situation and induces sympathetic (Maximino et al., 2014) and corticosteroid activity (Abreu et al., 395 2017), it is possible that long-term changes in behavior after CAS exposure could be used to model 396 post-traumatic stress disorder (PTSD). PTSD presents two central features: exposure to an event 397 that involves life-threatening or serious injury to themselves or others, linked to intense fear, 398 despair, or horror (Olff et al., 2005; Miller \& McEwen, 2006; Rao et al., 2009). In response to this 399 traumatic event, some symptoms are developed, such as flashbacks of the traumatic event, 400 avoidance of stimuli associated to the event, hypervigilance, and hyperexcitability (Figueira \& 401 Mendlowicz, 2003). Importantly, PTSD is defined as a delayed response to the life-threatening 402 situation, since, in order to be diagnosed with PTSD the individual needs to experience symptoms at 403 least 6 months after the traumatic event (American Psychiatric Association, 2013). The frequency 404 and the degree to which an individual is anxious or afraid are extremely important for the diagnosis 405 of certain psychiatric disorders.

Currently, rodent models for PTSD are based on the animal's exposure to extreme stress 407 situations, resulting in intense fear responses in the animal (Matar et al., 2013). After exposure to a 408 stressful protocol, usually involving the presentation of a predator or partial predator stimulus, the 409 animal displays behavioral characteristics that are similar to those found in PTSD, including 410 increased anxiety- or depressive-like behavior (Cohen et al., 2011; Matar et al., 2013).

In zebrafish, the use of prolonged exposure to a predator has been proposed as a model for

412 PTSD (Stewart et al., 2014a); while this setup produces protracted predator avoidance, it is not able 413 to model situations in which the traumatic event is brief, a requirement for adequate models for 414 PTSD (Yehuda \& Antelman, 1993). We have exploited CAS as a stimulus to induce a PTSD-like 415 syndrome in zebrafish (Lima et al., 2015, 2016). PTSD produced anxiety-like behavior that is 
416 qualitatively and quantitatively different $24 \mathrm{~h}$ after exposure than immediately after exposure,

417 suggesting that the stress-free period leads to incubation of stress/fear responses instead of merely

418 producing a sustained response (Lima et al., 2016). Moreover, the sensitization was observed in two

419 different tests for anxiety-like behavior, as well as in startle responses, modeling two domains

420 (anxiety and hypervigilance) that are altered in PTSD (Lima et al., 2016). Finally, this time-

421 dependent sensitization does not affect all animals equally, with about one-quarter of the animals

422 showing maladaptive responses, and another quarter displaying resilience (Lima et al., 2016).

423 Currently, the model is being used to evaluate the role of nitric oxide on PTSD (see also Lima et al., 424 2015).

425 Recently, the observation that zebrafish CAS produces different behavioral phenotypes 426 during and after exposure (Box 2) led us to propose using these responses as models for panic 427 attacks and panic disorder, respectively (Silva et al., 2018). Tracing a parallel with two types of 428 freezing evoked by electrical stimulation of the dorsal periaqueductal gray area (dPAG) of rats 429 dPAG-evoked freezing and post-stimulation freezing (Brandão et al., 2008) - we proposed that the 430 increase in erratic swimming that is consistently observed during CAS exposure (Box 2) is an 431 escape (panic-like) response, while the increase in freezing that is observed post-exposure is more 432 associated with risk assessment (anxiety-like, allowing the animal to evaluate the consequences of 433 the aversive stimulus). This model is currently being used to evaluate the role of the serotonergic 434 system on both responses.

\section{Conclusions}

Our current knowledge on alarm substances and disturbance signals increased considerably 438 since Pfeiffer (1977) described its distribution and Smith (1992) suggested hypotheses for its 439 evolution. It is now known that alarm substances evolved independently in other fish species, and 440 that can be independent from club cells, raising the question of alternative mechanisms for CAS 
441 production. While most of the focus in the past has been on the ecological consequences of CAS

442 and its adaptive functions, research in the last 20 years focused mainly on the neural basis of CAS

443 detection and alarm reaction generation. These two research traditions rarely cross-fertilized each

444 other; however, good ethological validation, ecological relevance, and adequate knowledge of the

445 neural bases of a given behavioral function is crucial for its use as a model system in the behavioral 446 neurosciences and neuropharmacology (van der Staay, 2006; Maximino, 2017). As a result - and as

447 a consequence of the ascension of zebrafish as a model organism in the field (Kalueff et al., 2014;

448 Stewart et al., 2014b; Shams et al., 2018) - more focus has been given on the applications of CAS

449 as an aversive stimulus in many different paradigms, from aversive conditioning (Ruhl et al., 2017;

450 Maximino et al., 2018) to behavioral models in psychopathology (see Box 2).

451 Many important research questions remain. What, if any, is the functional significance of 452 species differences in stimulus detection? Given that CAS induce sympathetic activity and 453 glucocorticoid release, what are the effects of alarm substances (and disturbance signals) on 454 metabolism (e.g., glucose production, osmoregulation, oxidative metabolism)? What is the role of 455 environmental niches (e.g., substrate, water turbidity, water flow velocity) on the behavioral effects 456 of CAS? How specific mediators (serotonin, glucocorticoids, catecholamines) produce variation in 457 these responses? Is there a relationship between the environment in which a species evolved CAS 458 and variation in these neural systems? These are relevant gaps in the literature that await further 459 investigation.

\section{Acknowledgments}

462 This work first appeared as a preprint on preprints.org (doi:10.20944/preprints201803.0279.v1 ).

$463 \mathrm{CM}$ is a recipient of a CNPq grant (Edital Universal 2016, Processo 400726/2016-6). MGL is a 464 recipient of a CNPq grant (Edital Universal 2016; Processo 423735/2016-0). 
466

467

468

469

470

\section{References}

Abreu, M. S., Giacomini, A. C. V. V., Koakoski, G., Piato, A. L. S. \& Barcellos, L. J. G. (2017) Divergent Effect of Fluoxetine on the Response to Physical or Chemical Stressors in Zebrafish. PeerJ 5, e3330.

Agetsuma, M., Aizawa, H., Aoki, T., Nakayama, R., Takahoko, M., Sassa, T., Amo, R., Shiraki, T., Goto, M., Kawakami, K., et al. (2010) The Habenula Is Crucial for Experience-Dependent Modification of Fear Responses in Zebrafish. Nature Neuroscience 13, 1354-1356.

Alemadi, S. D. \& Wisenden, B. D. (2002) Antipredator Response to Injury-Released Chemical Alarm Cues by Convict Cichlid Young before and after Independence from Parental Protection. Behaviour 139, 603-611.

American Psychiatric Association. (2013) Diagnostic and Statistical Manual of Mental Disorders Fifth Edition - DSM-5, 5th ed. Washington: American Psychiatric Publishing.

Amo, R., Fredes, F., Kinoshita, M., Aoki, R., Aizawa, H., Agetsuma, M., Aoki, T., Shiraki, T., Kakinuma, H., Matsuda, M., et al. (2014) The Habenulo-Raphe Serotonergic Circuit Encodes an Aversive Expectation Value Essential for Adaptive Active Avoidance of Danger. Neuron 84, 10341048.

Barcellos, L. J. G., Volpato, G. L., Barreto, R. E., Coldebella, I. \& Ferreira, D. (2011) Chemical Communication of Handling Stress in Fish. Physiology \& Behavior 103, 372-375.

Barcellos, L. J. G., Koakoski, G., Ferreira, D., Barreto, R. E. \& Volpato, G. L. (2014) Chemical Communication of Predation Risk in Zebrafish Does Not Depend on Cortisol Increase. Scientific Reports 4, 5076.

Barreto, R. E., Barbosa-Júnior, A., Urbinati, E. C. \& Hoffmann, A. (2014) Cortisol Influences the Antipredator Behavior Induced by Chemical Alarm Cues in the Frillfin Goby. Hormones and Behavior 65, 394-400.

Bazáes, A., Olivares, J. \& Schmachtenberg, O. (2013) Properties, Projections, and Tuning of Teleost Olfactory Receptor Neurons. Journal of Chemical Ecology 39, 451-464.

Biechl, D., Tietje, K., Ryu, S., Grothe, B., Gerlach, G. \& Wullimann, M. F. (2017) Identification of Accessory Olfactory System and Medial Amygdala in the Zebrafish. Scientific Reports 7, 44295.

Blanchard, D. C., Griebel, G. \& Blanchard, R. J. (2003) Conditioning and Residual Emotionality Effects of Predator Stimuli: Some Reflections on Stress and Emotion. Progress in NeuroPsychopharmacology and Biological Psychiatry 27, 1177-1185.

Brandão, M. L., Zanoveli, J. M., Ruiz-Martinez, R. C., Oliveira, L. C. \& Landeira-Fernandez, J. (2008) Different Patterns of Freezing Behavior Organized in the Periaqueductal Gray of Rats: Association with Different Types of Anxiety. Behavioural Brain Research 188, 1-13. 
500 Braubach, O. R., Fine, A. \& Croll, R. P. (2012) Distribution and Functional Organization of 501 Glomeruli in the Olfactory Bulbs of Zebrafish (Danio Rerio). Journal of Comparative Neurology 502 520, 2317-2339.

503 Brown, G. E., Adrian Jr, J. C., Smyth, E., Leet, H. \& Brennan, S. (2000) Ostariophysan Alarm 504 Pheromones: Laboratory and Field Tests of the Functional Significance of Nitrogen Oxides. Journal 505 of Chemical Ecology 26, 139-154.

506 Canzian, J., Fontana, B. D., Quadros, V. A. \& Rosemberg, D. B. (2017) Conspecific Alarm 507 Substance Differently Alters Group Behavior of Zebrafish Populations: Putative Involvement of 508 Cholinergic and Purinergic Signaling in Anxiety- and Fear-like Responses. Behavioural Brain 509 Research 320, 255-263.

510 Chivers, D. P. \& Smith, R. J. F. (1994) Intra- and Interspecific Avoidance of Areas Marked with 511 Skin Extract from Brook Sticklebacks (Culaea Inconstans) in a Natural Habitat. Journal of 512 Chemical Ecology 20, 1517-1524.

513 Chivers, D. P., Brown, G. E. \& Smith, R. J. F. (1996) The Evolution of Chemical Alarm Signals: 514 Attracting Predators Benefits Alarm Signal Senders. American Naturalist 148, 649-659.

515 Chivers, D. P., Wisenden, B. D., Hindman, C. J., Michalak, T. A., Kusch, R. C., Kaminskyi, S. G. 516 W., Lack, K. L., Ferrari, M. C. O., Pollock, R. J., Halbgewachs, C. F., et al. (2007) Epidermal 517 'Alarm Substance' Cells of Fishes Maintained by Non-Alarm Functions: Possible Defense against 518 Pathogens, Parasites and UVB Radiation. Proceedings of the Royal Society B 274, 2611-2619.

519 Choi, J.-H., Jeong, Y.-M., Kim, S., Lee, B., Ariyasiri, K., Kim, H.-T., Jung, S.-H., Hwang, K.-S., 520 Choi, T.-I., Park, C. O., et al. (2017) Targeted Knockout of a Chemokine-like Gene Increases 521 Anxiety and Fear Responses. Proceedings of the National Academy of Sciences.

522 Chou, M., Amo, R., Kinoshita, M., Cherng, B., Shimazaki, H., Agetsuma, M., Aoki, T., Takahoko, 523 M., Yamazaki, M. \& Okamoto, H. (2016) Social Conflict Resolution Regulated by Two Dorsal 524 Habenular Subregions in Zebrafish. 352, 599-602.

525 Cohen, H., Kozlovsky, N., Alona, C., Matar, M. A. \& Joseph, Z. (2011) Animal Model for PTSD: 526 From Clinical Concept to Translational Research. Neuropharmacology 1-10.

527 Coppens, C. M., de Boer, S. F. \& Koolhaas, J. M. (2010) Coping Styles and Behavioural Flexibility:

528 Towards Underlying Mechanisms. Philosophical Transactions of the Royal Society Part B 365, 529 4021-4028.

530 DeCarvalho, T. N., Akitake, C. M., Thisse, C., Thisse, B. \& Halpern, M. E. (2013) Aversive Cues 531 Fail to Activate Fos Expression in the Asymmetric Olfactory-Habenula Pathway of Zebrafish.

532 Frontiers in Neural Circuits 7, Article 98.

533 Dielenberg, R. A. \& McGregor, I. S. (2001) Defensive Behavior in Rats towards Predatory Odors: A 534 Review. Neuroscience and Biobehavioral Reviews 25, 597-609.

535 Dielenberg, R. A. \& McGregor, I. S. (2006) Defensive Behavior in Rats towards Predatory Odors: A 536 Review. Neuroscience \& Biobehavioral Reviews 25, 597-609. 
537 Døving, K. B. \& Lastein, S. (2009) The Alarm Reaction in Fishes - Odorants, Modulations of 538 Responses, Neural Pathways. Annals of the New York Academy of Sciences 1170, 413-423.

539 Eachus, H., Bright, C., Cunliffe, V. T., Placzek, M., Wood, J. D. \& Watt, P. J. (2017) Disrupted-in540 Schizophrenia-1 Is Essential for Normal Hypothalamic-Pituitary-Interrenal (HPI) Axis Function. 541 Human Molecular Genetics 26, 1992-2005.

542 Egan, R. J., Bergner, C. L., Hart, P. C., Cachat, J. M., Canavello, P. R., Elegante, M. F., Elkhayat, S. 543 I., Bartels, B. K., Tien, A. K., Tien, D. H., et al. (2009) Understanding Behavioral and Physiological 544 Phenotypes of Stress and Anxiety in Zebrafish. Behavioural Brain Research 205, 38-44.

545 Eisthen, H. L. (1992) Phylogeny of the Vomeronasal System and of Receptor Cell Types in the 546 Olfactory and Vomeronasal Epithelia of Vertebrates. Microscopy Research and Technique 23, 1-21.

547 Fanselow, M. S. \& Lester, L. (1988) A Functional Behavioristic Approach to Aversively Motivated 548 Behavior: Predatory Imminence as a Determinant of the Topography of Defensive Behavior. In 549 Evolution and Learning (Bolles, R. C., Beecher, M. D., eds), pp. 185-211 Hillsdale: Erlbaum.

550 Faustino, A. I., Tacão-Monteiro, A., Oliveira, R. F., Parichy, D. M., Landgraf, R. \& Herculano, A. 551 M. (2017) Mechanisms of Social Buffering of Fear in Zebrafish. Scientific Reports 7, 44329.

552 Figueira, I. \& Mendlowicz, M. V. (2003) Diagnosis of Posttraumatic Stress Disorder. Revista 553 Brasileira de Psiquiatria 25, 12-16.

554 Folgueira, M., Anadón, R. \& Yáñez, J. (2004) An Experimental Study of the Connections of the 555 Telencephalon in the Rainbow Trout (Oncorhynchus Mykiss). I: Olfactory Bulb and Ventral Area. 556 Journal of Comparative Neurology 480, 180-203.

557 von Frisch, K. (1938) Zur Psychologie Des Fisch-Schwarmes. Naturwissenschaften 26, 601-606.

558 von Frisch, K. (1941) Über Einen Schreckstoff Der Fischhaut Und Seine Biologische Bedeutung. 559 Zeitschrift für vergleichende Physiologie 29, 46-145.

560 Gayoso, J., Castro, A., Anadón, R. \& Manso, M. J. (2012) Crypt Cells of the Zebrafish Danio Rerio 561 Mainly Project to the Dorsomedial Glomerular Field of the Olfactory Bulb. Chemical Senses 37, $562 \quad 357-369$.

563 Gayoso, J. Á., Castro, A., Anadón, R. \& Manso, M. J. (2011) Differential Bulbar and Extrabulbar 564 Projections of Diverse Olfactory Receptor Neuron Populations in the Adult Zebrafish (Danio 565 Rerio). Journal of Comparative Neurology 519, 247-276.

566 Gerlach, G. \& Lysiak, N. (2006) Kin Recognition and Inbreeding Avoidance in Zebrafish, Danio 567 Rerio, Is Based on Phenotype Matching. Animal Behaviour 71, 1371-1377.

568 Goodson, J. L. \& Kingsbury, M. A. (2013) What's in a Name? Considerations of Homologies and 569 Nomenclature for Vertebrate Social Behavior Networks. Hormones and Behavior 64, 103-112.

570 Halbgewachs, C. F., Kusch, R. C., Marchant, T. A. \& Chivers, D. P. (2009) Epidermal Club Cells 571 and the Innate Immune System of Minnows. Proceedings of the Royal Society B 98, 891-897. 
572 Hall, D. \& Suboski, M. D. (1995a) Sensory Preconditioning and Second-Order Conditioning of 573 Alarm Reactions in Zebra Danio Fish (Brachydanio Rerio). Journal of Comparative Psychology 574 109, 76-84.

575 Hall, D. \& Suboski, M. D. (1995b) Visual and Olfactory Stimuli in Learned Release of Alarm 576 Reactions by Zebra Danio Fish (Brachydanio Rerio). Neurobiology of Learning and Memory 63, $577 \quad 229-240$.

578 Halpern, M. E., Liang, J. O. \& Gamse, J. T. (2003) Leaning to the Left: Laterality in the Zebrafish 579 Forebrain. Trends in Neurosciences 26, 308-313.

580 Hamdani, E.-H., Stabell, O. B., Alexander, G. \& Døving, K. B. (2000) Alarm Reaction in the 581 Crucian Carp Is Mediated by the Medial Bundle of the Medial Olfactory Tract. Chemical Senses 25, $582 \quad 103-109$.

583 Hamdani, E. H. \& Døving, K. B. (2002) The Alarm Reaction in Crucian Carp Is Mediated by 584 Olfactory Neurons with Long Dendrites. Chemical Senses 27, 395-398.

585 Hamdani, E. H. \& Døving, K. B. (2003) Sensitivity and Selectivity of Neurons in the Medial 586 Region of the Olfactory Bulb to Skin Extract from Conspecifics in Crucian Carp, Carassius 587 Carassius. Chemical Senses 28, 181-189.

588 Hamdani, E. H. \& Døving, K. B. (2006) Specific Projection of the Sensory Crypt Cells in the 589 Olfactory System in Crucian Carp, Carassius Carassius. Chemical Senses 31, 63-67.

590 Hamilton, W. D. (1963) The Evolution of Altruistic Behavior. American Naturalist 97, 354-356.

591 Hansen, A. \& Zeiske, E. (1998) The Peripheral Olfactory Organ of the Zebrafish, Danio Rerio: An 592 Ultrastructural Study. Chemical Senses 23, 39-48.

593 Hüttel, R. (1941) Die Chemische Untersuchung Des Schreckstoffes Aus Elritzenhaut.

594 Naturwissenschaften 29, 333-334.

595 Jaiswal, S. K. \& Waghray, S. (1990) Quantification of Defense Reactions of Cichlid Fish,

596 Oreochromis Mossambicus (Peters) Trewavas, in Response to Warning Chemicals,. Indian Journal 597 of Animal Science 60, 1137-1145.

598 Jesuthasan, S. J. \& Mathuru, A. S. (2008) The Alarm Response in Zebrafish: Innate Fear in a 599 Vertebrate Genetic Model. Journal of Neurogenetics 22, 211-229.

600 Jordão, L. C. \& Volpato, G. L. (2000) Chemical Transfer of Warning Information in Non-Injured 601 Fish. Behaviour 137, 681-690.

602 Kalueff, A. V, Stewart, A. M. \& Gerlai, R. (2014) Zebrafish as an Emerging Model for Studying 603 Complex Brain Disorders. Trends in Pharmacological Sciences 35, 63-75.

604 Kermen, F., Franco, L. M., Wyatt, C. \& Yaksi, E. (2013) Neural Circuits Mediating Olfactory605 Driven Behavior in Fish. Frontiers in Neural Circuits 7, Article 62. 
606 Koolhaas, J. M., de Boer, S. F., Coppens, C. M. \& Buwalda, B. (2010) Neuroendocrinology of 607 Coping Styles: Towards Understanding the Biology of Individual Variation. Frontiers in 608 Neuroendocrinology 31, 307-321.

609 Krishnan, S., Mathuru, A. S., Kibat, C., Rahman, M., Lupton, C. E., Stewart, J., Claridge-Chang, A., 610 Yen, S. C. \& Jesuthasan, S. (2014) The Right Dorsal Habenula Limits Attraction to an Odor in 611 Zebrafish. Current Biology 24, 1167-1175.

612 Lastein, S., Hamdani, E. H. \& Døving, K. B. (2008) Single Unit Responses to Skin Odorants from 613 Conspecifics and Heterospecifics in the Olfactory Bulb of Crucian Carp Carassius Carassius. 614 Journal of Experimental Biology 211, 3529-3535.

615 Lawrence, B. J. \& Smith, R. J. F. (1989) Behavioral Response of Solitary Fathead Minnows, 616 Pimephales Promelas, to Alarm Substance. Journal of Chemical Ecology 15, 209-219.

617 Liley, N. R. (1982) Chemical Communication in Fish. Canadian Journal of Fisheries and Aquatic 618 Sciences 39, 22-35.

619 Lillesaar, C. (2011) The Serotonergic System in Fish. Journal of Chemical Neuroanatomy 41, 294 620308.

621 Lima, M. G., Silva, S. de N. dos S., Silva, R. X. do C., Oliveira, K. R. H. M., Batista, E. de J. O., 622 Maximino, C. \& Herculano, A. M. (2015) Putative Involvement of the Nitrergic System on the 623 Consolidation, but Not Initiation, of Behavioral Sensitization after Conspecific Alarm Substance in 624 Zebrafish. Pharmacology, Biochemistry \& Behavior 139, 127-133.

625 Lima, M. G., Silva, R. X. do C., Silva, S. de N. dos S., Rodrigues, L. do S. dos S., Oliveira, K. R. H. 626 M., Batista, E. de J. O., Maximino, C. \& Herculano, A. M. (2016) Time-Dependent Sensitization of 627 Stress Responses in Zebrafish: A Putative Model for Post-Traumatic Stress Disorder. Behavioural 628 Processes 128, 70-82.

629 Lima, S. L. \& Dill, L. M. (1990) Behavioral Decisions Made under the Risk of Predation: A Review 630 and Prospectus. Canadian Journal of Zoology 68, 619-640.

631 Mansur, B. D. M., dos Santos, B. R. \& Gouveia Jr, A. (2014) Efeitos Da Substância de Alarme No 632 Teste Claro/escuro No Zebrafish, Danio Rerio. Biota Amazônia 4, 87-93.

633 Matar, M. A., Zohar, J. \& Cohen, H. (2013) Translationally Relevant Modeling of PTSD in 634 Rodents. Cell and Tissue Research 354, 127-139.

635 Mathis, A. \& Smith, R. J. F. (1993) Chemical Alarm Signals Increase the Survival Time of Fathead 636 Minnows (Pimephales Promelas) during Encounters with Northern Pike (Esox Lucius). Behavioral 637 Ecology 4, 260-265.

638 Mathis, A., Chivers, D. P. \& Smith, R. J. F. (1995) Chemical Alarm Signals: Predator Deterrents or 639 Predator Attractants? American Naturalist 145, 994-1005.

640 Mathuru, A. S. (2016) Conspecific Injury Raises an Alarm in Medaka. Scientific Reports 6, 36615. 
641 Mathuru, A. S. \& Jesuthasan, S. (2013) The Medial Habenula as a Regulator of Anxiety in Adult 642 Zebrafish. Frontiers in Neural Circuits 7, Article 99.

643 Mathuru, A. S., Kibat, C., Cheong, W. F., Shui, G., Wenk, M. R., Friedrich, R. W. \& Jesuthasan, S. 644 (2012) Chondroitin Fragments Are Odorants That Trigger Fear Behavior in Fish. Current Biology $64522,538-544$.

646 Maximino, C. (2011) Modulation of Nociceptive-like Behavior in Zebrafish (Danio Rerio) by 647 Environmental Stressors. Psychology \& Neuroscience 4, 149-155.

648 Maximino, C. (2017) Behavioral Models in Psychopathology: Practical, Epistemic, and Semantic 649 Issues. PsyArxiv Preprints.

650 Maximino, C., Lima, M. G., Oliveira, K. R. M., Picanço-diniz, D. L. W. \& Herculano, A. M. (2011) 651 Adenosine A1, but Not A2, Receptor Blockade Increases Anxiety and Arousal in Zebrafish. Basic \& 652 Clinical Pharmacology \& Toxicology 109, 203-207.

653 Maximino, C., Lima, M. G., Oliveira, K. R. M., Batista, E. de J. O. \& Herculano, A. M. (2013) 654 'Limbic Associative' and 'autonomic' amygdala in Teleosts: A Review of the Evidence. Journal of 655 Chemical Neuroanatomy 48-49, 1-13.

656 Maximino, C., Lima, M. G., Costa, C. C., Guedes, I. M. L. \& Herculano, A. M. (2014) Fluoxetine 657 and WAY 100,635 Dissociate Increases in Scototaxis and Analgesia Induced by Conspecific Alarm 658 Substance in Zebrafish (Danio Rerio Hamilton 1822). Pharmacology, Biochemistry, and Behavior 659 124C, 425-433.

660 Maximino, C., Gemaque, J., Benzecry, R., Lima, M. G., Batista, E. de J. O., Picanço-Diniz, D. W., 661 Oliveira, K. R. M. \& Herculano, A. M. (2015) Role of Nitric Oxide in the Behavioral and 662 Neurochemical Effects of IB-MECA in Zebrafish. Psychopharmacology 232, 1671-1680.

663 Maximino, C., Meinerz, D. L., Fontana, B. D., Mezzomo, N. J., Stefanello, F. V., de S. Prestes, A., 664 Batista, C. B., Rubin, M. A., Barbosa, N. V., Rocha, J. B. T., et al. (2018) Extending the Analysis of 665 Zebrafish Behavioral Endophenotypes for Modeling Psychiatric Disorders: Fear Conditioning to 666 Conspecific Alarm Response. Behavioural Processes 149, 35-42.

667 Miller, M. M. \& McEwen, B. S. (2006) Establishing an Agenda for Translational Research on 668 PTSD. Annals of the New York Academy of Sciences 1071, 294-312.

669 Miyasaka, N., Morimoto, K., Tsubokawa, T., Higashijima, S., Okamoto, H. \& Yoshihara, Y. (2009) 670 From the Olfactory Bulb to Higher Brain Centers: Genetic Visualization of Secondary Olfactory 671 Pathways in Zebrafish. Journal of Neuroscience 29, 4756-4767.

672 Naish, K.-A., Carvalho, G. R. \& Pitcher, T. J. (1993) The Genetic Structure and Microdistribution of 673 Shoals of Phoxinus Phoxinus, the European Minnow. Journal of Fish Biology 43, 75-89.

674 Nathan, F. M., Ogawa, S., Parhar, I. S. \& Neurochemistry, J. O. F. (2015a) Kisspeptin1 Modulates 675 Odorant-Evoked Fear Response via Two Serotonin Receptor Subtypes (5-HT1A and 5-HT2) in 676 Zebrafish. Journal of Neurochemistry 133, 870-878. 
677 Nathan, F. M., Ogawa, S. \& Parhar, I. S. (2015b) Neuronal Connectivity between Habenular 678 Glutamate-Kisspeptin 1 Co-Expressing Neurons and the Raphe 5-HT System. Journal of 679 Neurochemistry 135, 814-829.

680 O'Connell, L. A. \& Hofmann, H. A. (2011) The Vertebrate Mesolimbic Reward System and Social 681 Behavior Network: A Comparative Synthesis. Journal of Comparative Neurology 519, 3599-3639.

682 Ogawa, S. \& Parhar, I. S. (2013) Anatomy of the Kisspeptin Systems in Teleosts. General and 683 Comparative Endocrinology 181, 169-174.

684 Ogawa, S., Ng, K. W., Ramadasan, P. N., Nathan, F. M. \& Parhar, I. S. (2012) Habenular Kiss1 685 Neurons Modulate the Serotonergic System in the Brain of Zebrafish. Endocrinology 153, 23986862407.

687 Ogawa, S., Nathan, F. M. \& Parhar, I. S. (2014) Habenular Kisspeptin Modulates Fear in the 688 Zebrafish. Proceedings of the National Academy of Sciences 111, 3841-3846.

689 Oka, Y. \& Korsching, S. I. (2011) Shared and Unique G Alpha Proteins in the Zebrafish versus 690 Mammalian Senses of Taste and Smell. Chemical Senses 36, 357-365.

691 Oka, Y., Saraiva, L. R. \& Korsching, S. I. (2012) Crypt Neurons Express a Single V1R-Related Ora 692 Gene. Chemical Senses 37, 219-227.

693 Okamoto, H., Agetsuma, M. \& Aizawa, H. (2011) Genetic Dissection of the Zebrafish Habenula, a 694 Possible Switching Board for Selection of Behavioral Strategy to Cope with Fear and Anxiety.

695 Developmental Neurobiology 72, 386-394.

696 Olff, M., Langeland, W. \& Gersons, B. P. R. (2005) The Psychobiology of PTSD: Coping with 697 Trauma. Psychoneuroendocrinology 30, 974-982.

698 Oliveira, T. A., Koakoski, G., Kreutz, L. C., Ferreira, D., da Rosa, J. G. S., de Abreu, M. S., 699 Giacomini, A. C. V., Oliveira, R. P., Fagundes, M., Piato, Â. L., et al. (2013) Alcohol Impairs 700 Predation Risk Response and Communication in Zebrafish. PLoS ONE 8, e75780.

701 Oliveira, T. A., Idalencio, R., Kalichak, F., dos Santos Rosa, J. G., Koakoski, G., de Abreu, M. S., 702 Giacomini, A. C. V., Gusso, D., Rosemberg, D. B., Barreto, R. E., et al. (2017) Stress Responses to 703 Conspecific Visual Cues of Predation Risk in Zebrafish. PeerJ 5, e3739.

704 Oswald, M. \& Robison, B. D. (2011) Strain-Specific Alteration of Zebrafish Feeding Behavior in 705 Response to Aversive Stimuli. Canadian Journal of Zoology 86, 1085-1094.

706 Parra, K. V, Adrian Jr, J. C. \& Gerlai, R. (2009) The Synthetic Substance Hypoxanthine 3-N-Oxide 707 Elicits Alarm Reactions in Zebrafish (Danio Rerio). Behavioural Brain Research 205, 336-341.

708 Perusini, J. N. \& Fanselow, M. S. (2015) Neurobehavioral Perspectives on the Distinction between 709 Fear and Anxiety. Learning \& Memory 22, 417-425.

710 Pfeiffer, W. (1977) The Distribution of Fright Reaction and Alarm Substance Cells in Fishes. 711 Copeia 4, 653-665. 
712 Pfeiffer, W. \& Riegelbauer, G. (1984) Effect of Hypoxanthine-3(N)-Oxide and Hypoxantine-1(N)-

713 Oxide on Central Nervous Excitation of the Black Tetra Gymnocorymbus Ternetzi (Charicidae,

714 Ostariophysi, Pisces) Indicated by Dorsal Light Response. Journal of Comparative Physiology A

715 123, 281-288.

716 Quadros, V. A., Silveira, A., Giuliani, G. S., Didonet, F., SIlveira, A. S., Nunes, M. E., Silva, T. O., 717 Loro, V. L. \& Rosemberg, D. B. (2016) Strain- and Context-Dependent Behavioural Responses of 718 Acute Alarm Substance Exposure in Zebrafish. Behavioural Processes 122, 1-11.

719 Rao, R. P., Suvrathan, A., Miller, M. M., McEwen, B. S. \& Chattarji, S. (2009) PTSD: From 720 Neurons to Networks. In Post-traumatic Stress Disorder: Basic Science and Clinical Practice 721 (Shiromani, P. J., Keane, T. M., LeDoux, J. E., eds), pp. 151-184 Nova Iorque: Humana Press.

722 Ruhl, T., Zeymer, M. \& von der Emde, G. (2017) Cannabinoid Modulation of Zebrafish Fear

723 Learning and Its Functional Analysis Investigated by c-Fos Expression. Pharmacology,

724 Biochemistry \& Behavior 153, 18-31.

725 Sanches, F. H. C., Miyai, C. A., Pinho-Neto, C. F. \& Barreto, R. E. (2015) Stress Responses to 726 Chemical Alarm Cues in Nile Tilapia. Physiology \& Behavior 149, 8-13.

727 Sato, Y., Miyasaka, N. \& Yoshihara, Y. (2005) Mutually Exclusive Glomerular Innervation by Two 728 Distinct Types of Olfactory Sensory Neurons Revealed in Transgenic Zebrafish. Journal of 729 Neuroscience 25, 4889-4897.

730 Schirmer, A., Jesuthasan, S. \& Mathuru, A. S. (2013) Tactile Stimulation Reduces Fear in Fish. 731 Frontiers in Behavioral Neuroscience 7, Article 167.

732 Servili, A., Le Page, Y., Leprince, J., Caraty, A., Escobar, S., Parhar, I. S., Seong, J. Y., Vaudry, H. \& 733 Kah, O. (2011) Organization of Two Independent Kisspeptin Systems Derived from Evolutionary734 Ancient Kiss Genes in the Brain of Zebrafish. Endocrinology 152, 1527-1540.

735 Shams, S., Rihel, J., Ortiz, J. G. \& Gerlai, R. T. (2018) The Zebrafish as a Promising Tool for 736 Modeling Human Brain Disorders: A Review Based upon an IBNS Symposium. Neuroscience \& 737 Biobehavioral Reviews 75, 176-190.

738 Silva, P. I. M., Martins, C. I. M., Khan, U. W., Gjøen, H. M., Øverli, Ø. \& Höglund, E. (2015) 739 Stress and Fear Responses in the Teleost Pallium. Physiology \& Behavior 141, 17-22.

740 Silva, R. X. do C., Rocha, S. P., Lima, M. G., Herculano, A. M., Rosemberg, D. B. \& Maximino, C. 741 (2018) Role of Serotonin on Behavioral Responses to Alarm Substance in Zebrafish: A Putative 742 Model for Panic Disorder. Pre-registered project on the Open Science Framework. 2018, 743 doi:10.17605/OSF.IO/BK85D.

744 Smith, R. J. F. (1992) Alarm Signals in Fishes. Reviews in Fish Biology and Fisheries 2, 33-63.

745 Smith, R. J. F. \& Lemly, A. D. (1986) Survival of Fathead Minnows after Injury by Predators and 746 Its Possible Role in the Evolution of Alarm Signals. Environmental Biology of Fishes 15, 147-149. 
747 Speedie, N. \& Gerlai, R. (2008) Alarm Substance Induced Behavioral Responses in Zebrafish 748 (Danio Rerio). Behavioural Brain Research 188, 168-177.

749 van der Staay, F. J. (2006) Animal Models of Behavioral Dysfunctions: Basic Concepts and 750 Classifications, and an Evaluation Strategy. Brain Research Reviews 52, 131-159.

751 Stephenson, J. F. (2016) Keeping Eyes Peeled: Guppies Exposed to Chemical Alarm Cue Are More 752 Responsive to Ambiguous Visual Cues. Behavioral Ecology and Sociobiology 70, 575-584.

753 Stewart, A. M., Yang, E., Nguyen, M. \& Kalueff, A. V. (2014a) Developing Zebrafish Models

754 Relevant to PTSD and Other Trauma- and Stressor-Related Disorders. Progress in

755 Neuropsychopharmacology \& Biological Psychiatry.

756 Stewart, A. M., Braubach, O., Spitsbergen, J., Gerlai, R. \& Kalueff, A. V. (2014b) Zebrafish Models 757 for Translational Neuroscience Research: From Tank to Bedside. Trends in Neurosciences 37, 264758278.

759 Ubeda-Bañon, I., Pro-Sistiaga, P., Mohedano-Moriano, A., Saiz-Sanchez, D., de la Rosa-Prieto, C., 760 Gutierrez-Castellanos, N., Lanuza, E., Martínez-Garcia, F. \& Martinez-Marcos, A. (2011) Cladistic 761 Analysis of Olfactory and Vomeronasal Systems. Frontiers in Neuroanatomy 5, Article3.

762 Weiss, J. M. (1968) Effects of Coping Responses on Stress. Journal of Comparative Physiology 65, $763251-260$.

764 Whitlock, K. E. (2006) The Sense of Scents: Olfactory Behaviors in the Zebrafish. Zebrafish 3, $765203-213$.

766 Wiseden, B. D. \& Smith, R. J. F. (1998) A Re-Evaluation of the Effect of Shoalmate Familiarity on 767 the Proliferation of Alarm Substance Cells in Ostariophysan Fishes. Journal of Fish Biology 53, 768 841-846.

769 Wiseden, B. D. \& Thiel, T. A. (2002) Field Verification of Predator Attraction to Minnow Alarm 770 Substance. Journal of Chemical Ecology 28, 433-438.

771 Wisenden, B. D., Chivers, D. P., Brown, G. E. \& Smith, R. J. F. (1995) The Role of Experience in 772 Risk Assessment: Avoidance of Areas Chemically Labelled with Fathead Minnow Alarm

773 Pheromone by Conspecifics and Heterospecifics. Écoscience 2, 116-122.

774 Yehuda, R. \& Antelman, S. M. (1993) Criteria for Rationally Evaluating Animal Models of 775 Posttraumatic Stress Disorder. Biological Psychiatry 33, 479-486.

776 Yunker, W. K., Wein, D. E. \& Wisenden, B. D. (1999) Conditioned Alarm Behavior in Fathead 777 Minnows (Pimephales Promelas) Resulting from Association of Chemical Alarm Pheromone with a 778 Nonbiological Visual Stimulus. Journal of Chemical Ecology 25, 2677-2686. 


\section{Figure captions}

\section{Figure 1 - Alarm (CAS) and disturbance (DS) signals increase post-encounter defensive}

781 behavior. On the left the predatory imminence theory of defensive behavior (Fanselow \& Lester,

782 1988) is represented; antipredatory behavior develops from pre-encounter defensive behavior (risk

783 assessment behavior) to post-encounter defensive behavior (adjustments to avoid detection) and

784 circa-strike defensive behavior (adjustments to escape or fight the predator); these stages are

785 associated with anxiety, fear, and panic (left arrow; Perusini \& Fanselow, 2015). On the right the

786 predator sequence of Lima \& Dill (1990) is presented (adapted from Smith, 1992): a prey-predator

787 encounter (i.e., post-encounter situation) develops to either a predatory attack (if either the predator

788 detects the prey first, or if the predator is first detected but avoidance is unsuccessful) or to

789 successful avoidance; a predatory attack (i.e., circa-strike situation) can develop to either capture or

790 successful escape. Conspecific alarm substance or disturbance signals increase the probability of

791 prey detecting the predator first and decrease the probability of the predator detecting the prey first;

792 as a consequence, these signals increase the probability of avoidance. Moreover, according to the

793 predator attraction hypothesis, CAS can also decrease the probability of a successful capture. 


\section{Predatory imminence theory} (Fanselow \& Lester, 1988)

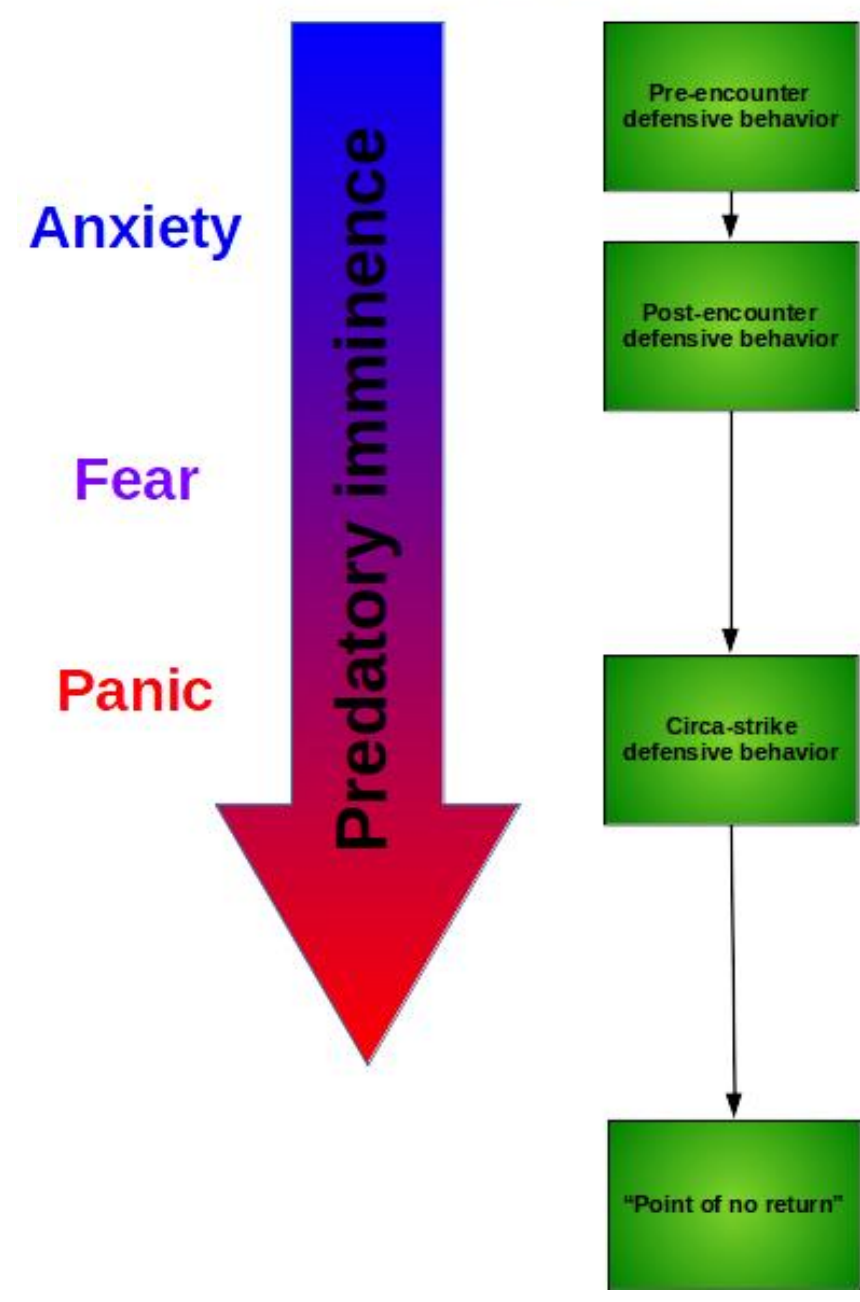

Predation sequence

(Lima \& Dill, 1990)

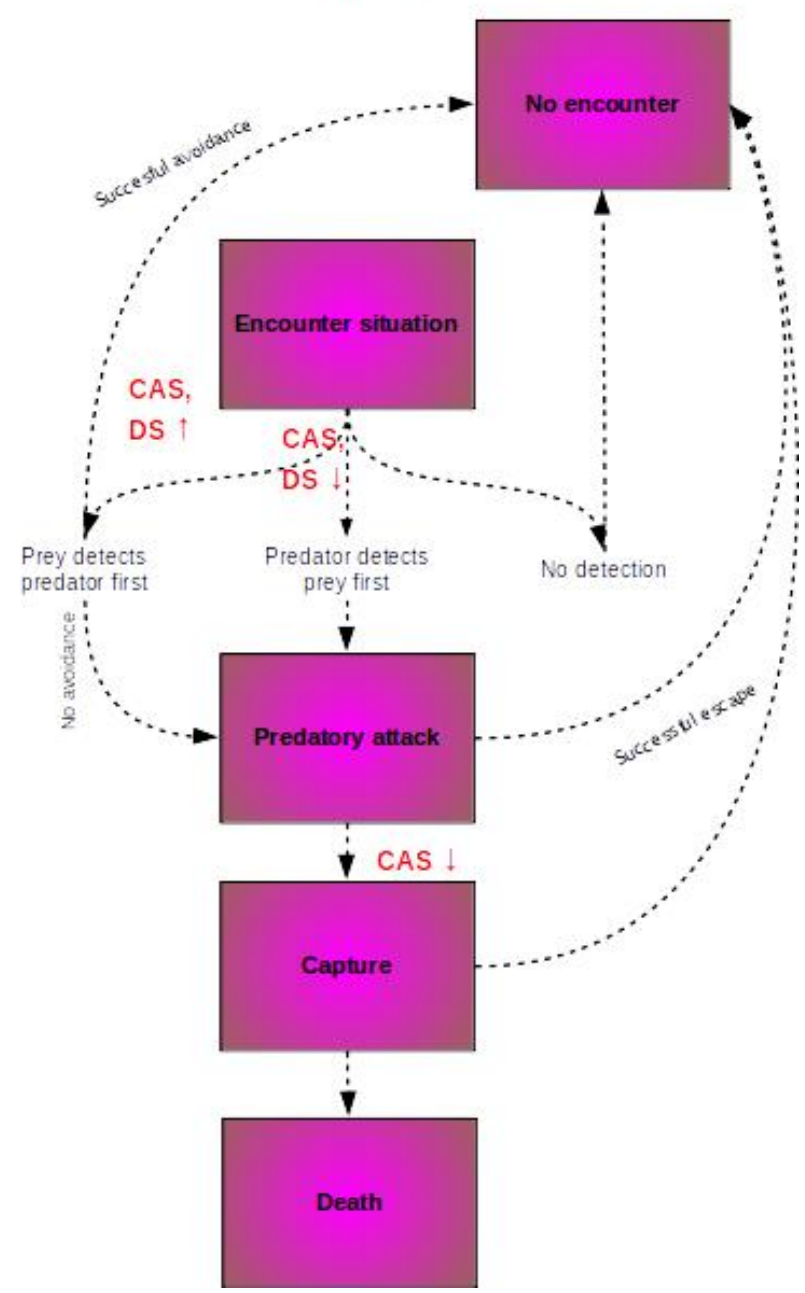


797 Figure 2 - The olfactory system of teleost fishes. Projections from the olfactory bulb (OB) course

798 through the lateral olfactory tract (LOT) or the medial olfactory tract (MOT). These tracts synapse 799 at the telencephalon (TE) at pallial (posterior zone of the dorsal telencephalon, Dp) and subpallial 800 regions (ventral zone of the ventral telencephalon, Vv); not depicted are MOT terminals at the 801 intermediate $(\mathrm{Vi})$ and postcommisural $(\mathrm{Vp})$ zones of the ventral telencephalon. In the diencephalon, 802 OB projections reach the dorsal habenula $(\mathrm{Hb})$ and the hypothalamus $(\mathrm{HT})$; a putative $\mathrm{Vv}$-posterior 803 tuberculum (PT) projection is also depicted (dashed green arrow), which gives rise to a motor 804 pathway that ends in the mesencephalic locomotor region (MLR) and reticulospinal tract (RST). Vv 805 also receives a direct projection from the olfactory epithelium (red arrow). Abbreviations: OE: 806 Olfactory epithelium; OB: Olfactory bulb; TE: telencephalon; Dp: posterior zone of the dorsal 807 telencephalon; Vv: ventral zone of the ventral telencephalon; Hb: Habenula; OT: optic tectum; PT: 808 posterior tuberculum; HT: Hypothalamus; CB: cerebellum; MLR: mesencephalic locomotor region; 809 RST: reticulospinal tract; SC: spinal cord. Based on Kermen et al., (2013).

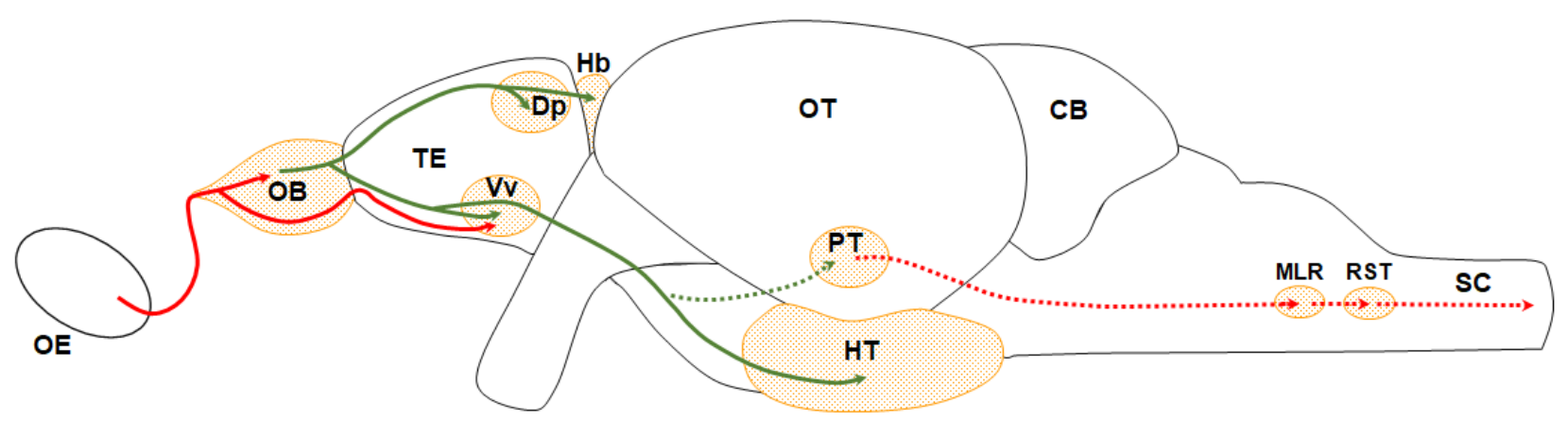


812 Figure 3 - The brain aversive system of teleosts. Structures involved in threat detection and

813 appraisal are shown, including structures which have been shown to be activated by CAS in 814 zebrafish (Faustino et al., 2017; Ruhl et al., 2017). The main circuit in the interpretation of

815 threatening stimulus is Dm, the homologue of the mammalian basolateral amygdala. This structure

816 projects to the precommissural (Vs) and supracommissural $(\mathrm{Vp})$ zones of the ventral telecephalon,

817 which project (putatively inhibitory) axons to the ventral ( $\mathrm{Vv})$, intermediate (Vi), and lateral (Vl)

818 zones of the ventral telencephalon, to the habenula $(\mathrm{Hb})$, and to the preoptic area (POA), as well as

819 projections to the caudal hypothalamus (Hc), optic tectum (OT), and central gray (GC). The POA

820 and the Hc generate the vegetative outputs of CAS (cortisol and norepinephrine/epinephrine

821 release), while OT and GC generate the behavioral outputs (fight/flight/freeze). Structures shown to

822 be activated by CAS are identified in pink.

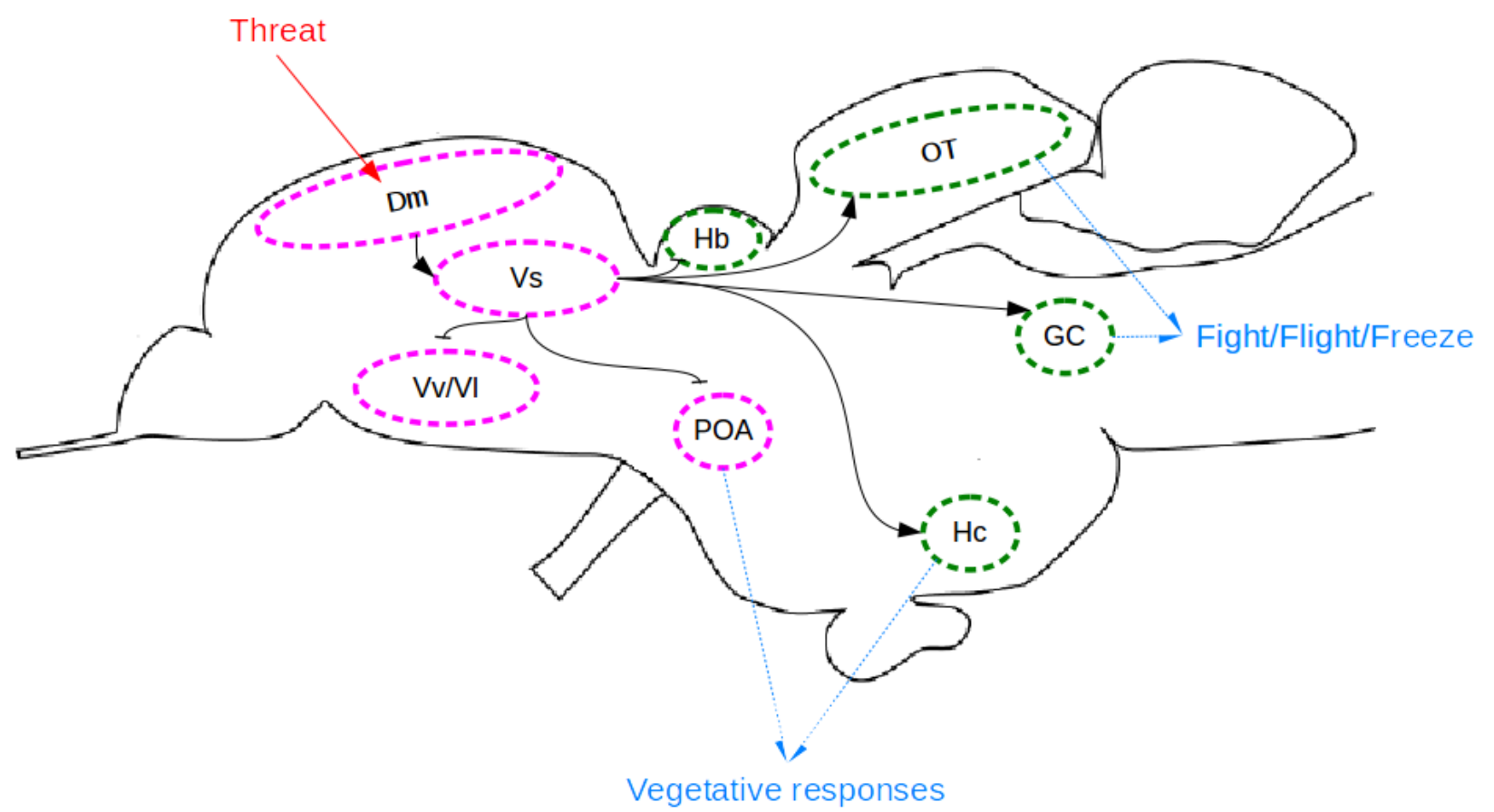




\section{Boxes}

\section{Box 1. Disturbance signals in fish}

Behavioral responses of fish depend on the type of threatening chemical cues. Fish use a combination of information and the context of the situation to determine their defensive strategies. While CASs are signals that are released after (potentially terminal) capture, disturbance signals (DS) involves the communication of predator threat without damage to the animal; one example of a disturbance signal is the alarm call of many birds and macaques, which, after visually detecting a predator, acoustically communicate this to their mates.

Chemical DSs have been demonstrated in some fish species. Unstressed Nile tilapia (Oreochromis niloticus) and jundiá (Rhamdia quelen) exposed to water in which a conspecific received handling stress show increased cortisol levels (Barcellos et al., 2011). Perhaps more ecologically relevant is the observation that information regarding predators is also transferred. In the pacu Piaractus mesopotamicus, the sight of a predator elicits antipredator behavior; unstressed pacus exposed to water in which a conspecific was visually exposed to a predator avoid the chemical stimulus (Jordão \& Volpato, 2000). Zebrafish show increased whole-body cortisol after being exposed to water from a conspecific that had visual contact with a predator fish (Oliveira et al., 2013); interestingly, even when whole-body cortisol is not increased in animals with visual contact with the predator, these endocrine responses are still observed in animals receiving chemical cues from these "donor" animals" (Barcellos et al., 2014). These results suggest the existence of chemical cues that are released in the water by non-injured fish (disturbance signals) to warn conspecifics of the presence of predators. Another interesting finding is that zebrafish visually exposed to a predator display antipredator behaviors, including tighter shoaling, that in its turn trigger defensive behavior in conspecifics which did not originally see the predator (Oliveira et al., 2017). The relationship between cortisol and behavioral responses, however, has not yet been determined, opening an interesting avenue of investigation. 


\section{Box 2. What are the behavioral effects of CAS?}

Fear can be defined as an adaptive reaction to an aversive stimulus that is necessary for moments of distal or proximal threat (such as the presence of a predator), generating either defensive fighting, freezing, or fleeing (Fanselow \& Lester, 1988; Perusini \& Fanselow, 2015). While exposure to certain threat is expected to induce fear-like behaviors, partial predator stimuli such as odors tend to elicit more risk assessment, but may also produce strong species-specific reaction defenses, including freezing and avoidance (Dielenberg \& McGregor, 2001). Since CAS is released by wounded fish, and not by the predator, it should be considered a partial predator stimulus, and therefore it is not clear whether the behavioral profile induced by CAS is fear-like.

While CAS behavioral effects have been described in many Ostariophysan and nonOstariophysan species, as described above, a more careful observation of the behavioral effects in laboratory setting has been made using zebrafish and fathead minnows. In the first species, CAS has been shown to elicit erratic swimming, freezing, shoal aggregation, jumps, and bottomdwelling (Table 1). Results from the literature are inconsistent, and appear to be associated with whether the substance is present or absent during testing (i.e., whether animals are observed during or after CAS exposure), and whether animals are tested alone or in groups. When animals are tested alone, there is a consistent increase in bottom-dwelling, freezing, and erratic swimming during exposure (Table 1), while there is considerable variation in those endpoints after exposure (Table 1). It is not clear what procedural variations lead to which effects after exposure, but certainly there is great variation in the literature. Zebrafish is a shoaling species, and, in nature, CAS is expected to function in shoals. As such, increased shoaling responses are consistently observed during CAS exposure (Table 1; Speedie \& Gerlai, 2008; Lima et al., 2016; Canzian et al., 2017; Choi et al., 2017). 


\section{i1. Fish tested alone}

\begin{tabular}{|c|c|c|}
\hline Endpoint & During exposure & After exposure \\
\hline \multirow[t]{7}{*}{ Geotaxis (Bottom-dwelling) } & Zebrafish & $\underline{\text { Zebrafish }}$ \\
\hline & $\uparrow$ (Nathan et al., 2015a; Eachus et al., 2017) & $\uparrow$ (Schirmer et al., 2013; Quadros et \\
\hline & & al., 2016) \\
\hline & $\underline{\text { Fathead minnow }}$ & 0 (Nathan et al., 2015a) \\
\hline & Not tested & \\
\hline & & $\underline{\text { Fathead minnow }}$ \\
\hline & & Not tested \\
\hline \multirow[t]{7}{*}{ Freezing } & $\underline{\text { Zebrafish }}$ & $\underline{\text { Zebrafish }}$ \\
\hline & $\uparrow$ (Ogawa et al., 2014; Nathan et al., 2015a; & $\uparrow$ (Egan et al., 2009; Quadros et al., \\
\hline & Maximino et al., 2018) & 2016) \\
\hline & & 0 (Nathan et al., 2015a) \\
\hline & $\underline{\text { Fathead minnow }}$ & \\
\hline & $\uparrow($ Lawrence \& Smith, 1989) & $\underline{\text { Fathead minnow }}$ \\
\hline & & Not tested \\
\hline \multirow[t]{5}{*}{ Erratic swimming } & $\underline{\text { Zebrafish }}$ & $\underline{\text { Zebrafish }}$ \\
\hline & $\uparrow($ Ogawa et al., 2014; Nathan et al., 2015a; & 0 (Nathan et al., 2015a) \\
\hline & Maximino et al., 2018) & $\uparrow($ Egan et al., 2009) \\
\hline & $\underline{\text { Fathead minnow }}$ & $\underline{\text { Fathead minnow }}$ \\
\hline & $\uparrow($ Lawrence \& Smith, 1989) & Not tested \\
\hline \multirow[t]{4}{*}{ Scototaxis (Dark preference) } & Not tested & $\underline{\text { Zebrafish }}$ \\
\hline & & $\uparrow$ (Maximino et al., 2014; Lima et al., \\
\hline & & 2016; Quadros et al., 2016) \\
\hline & & 0 (Mansur et al., 2014) \\
\hline
\end{tabular}




\section{$\underline{\text { Fathead minnow }}$}

Not tested

Risk assessment (light/dark Not tested

0 (Maximino et al., 2014; Quadros et

test)

al., 2016)

$\underline{\text { Fathead minnow }}$

Not tested

\section{Fish tested in shoals}

\begin{tabular}{lll}
\hline Endpoint & During exposure & After exposure \\
\hline Geotaxis & $\underline{\text { Zebrafish }}$ & Not tested \\
& 0 (Speedie \& Gerlai, 2008) & \\
& $\uparrow($ Canzian et al., 2017; Ruhl et al., 2017)
\end{tabular}

$\underline{\text { Fathead minnows }}$

$\uparrow($ Yunker et al., 1999)

Freezing

$\underline{\text { Zebrafish }}$

Not tested

0 (Speedie \& Gerlai, 2008; Canzian et al.,

2017)

Fathead minnows

Not tested

Erratic swimming

$\underline{\text { Zebrafish }}$

Not tested

$\uparrow$ (Speedie \& Gerlai, 2008; Canzian et al.,

2017)

$\underline{\text { Fathead minnows }}$

Not tested

Shoaling

Zebrafish

Not tested 
$\uparrow$ (Speedie \& Gerlai, 2008; Lima et al., 2016;

Canzian et al., 2017; Choi et al., 2017)

$\underline{\text { Fathead minnows }}$

Not tested

In addition to these effects, other important behavioral adjustments were also observed, in zebrafish, during or after CAS exposure. These adjustments include fear-induced analgesia (Maximino, 2011; Maximino et al., 2014), an inhibition of nocifensive behavior that is thought to allow receivers to flee even when they are injured. Moreover, CAS also serves as a platform for learning, as animals learn to avoid areas or cues which were previously associated with shreckstoff exposure (Hall \& Suboski, 1995a, 1995b; Ruhl et al., 2017; Maximino et al., 2018). Finally, as appears to be the case with predator odors in rodents (Blanchard et al., 2003), CAS can also produce long-term (time-dependent) sensitization of defensive responses (Lima et al., 2015, 2016), suggesting a basis for the creation of models for PTSD (Section 9). 